\title{
Frontier: Reflections on the Meaning and Fertility of This Concept in Amazonian Urban Studies
}

\author{
Antonio Di Campli \\ Interuniversity Department of Regional and Urban Studies and Planning, Polytechnic and University of Turin, Italy
}

Received December 13, 2019; Revised January 28, 2020; Accepted February 7, 2020

Copyright $\odot 2020$ by authors, all rights reserved. Authors agree that this article remains permanently open access under the terms of the Creative Commons Attribution License 4.0 International License

\begin{abstract}
Frontiers are generally defined as sparsely populated peripheral geographic areas compared to the political-economic centers in which demographic or accelerated technological processes are manifested. In Amazonia, the frontier have been characterized as the first wave of modernity to penetrate the coast of unexplored territories. The definitions of frontiers in the Amazon have been linked to colonial, imperial forces and capitalist economies. All have caused the arrival and formation of several social groups that, as a whole, have defined the long-term globalization process. But this region, in any case, does not fall within this definition. Modernity has reached its shores for centuries, and Amazonians have reacted in so many ways that Amazonian space and society is a fragmented skirt of time frames. In this sense, the hypothesis supported by this article, in urban and territorial studies, is that the common characterization of Amazonia as a frontier should be deeply revised. This territory has been part of the capitalist world system for more than five centuries and may be better be conceived and interpreted as a composition of enclave environments, economies and ecologies, whose relationships to external political and socio-economic powers is deeply rooted and far less fragile than the frontier usage implies. Methodologically, the analysis focuses on socio-spatial and territorial planning literature about Amazonia and concerninig Amazonian territorial constructions highlighting those many factors that seem to contribute to the continued plausibility of the frontier notion. Principal results are related to the construction of a critique to the sense, value and fertility of the concept of 'frontier' un urban and territorial planning practices in contemporary Amazonian territories.
\end{abstract}

Keywords Frontier, Amazonia, Urban Planning, Territorial Planning

\section{Introduction}

In many urban and territorial studies the notion of frontier is the organizing theme of Amazonian environmental and socio-political history.

Frontiers are generally defined as sparsely populated peripheral geographic areas compared to the political-economic centers in which demographic or accelerated technological processes are manifested. Frontier have been characterized as the first wave of modernity to penetrate the coast of unexplored land. Amazonia, in any case, does not fall within this definition. Modernity has reached its shores for centuries, and Amazonians have reacted in so many ways that Amazonian space and society is a fragmented skirt of time frames.

The definitions of frontiers in the Amazon have been linked to colonial, imperial forces and capitalist economies. All have caused the arrival and formation of several social groups that, as a whole, have defined the long-term globalization process.

The Amazonian frontier first presented before expansionary European societies in the 16th century looks similar to what Wallerstein (1974) has referred to as an external arena, or perhaps more accurately a low-value external arena. While the primitive accumulation of the New World gold and silver represented an absolute shift in value towards the core in such the same way as the appropriation of African slaves by the New World enterprise represented an absolute transfer (from an external arena) into the emergent core-periphery dynamic of the modern worlds system, the Amazonian contribution was negligible. Amazonia represented a frontier, but one whose integration into the dynamic of expropriation was marginal. It wasn't a frontier that particularly mattered. It was the world system, but didn't present itslf that way. It had little role to play either in terms of labour (the demographic consequences of Conquest having been dramatic) or in terms of highly desirable extractive resources, but it has periodically been inserted / re-inserted 
into the global trade since its Conquest. As other sources of key extractive / primary resources have disappeared (such as timber from previously cheaper sources in South-eastAsia and central Africa, or bauxite and iron ore located close to fluvial transport). Amazonia has been reintroduced as an alternative supplier. Earlier, in the same way, the Amazonian rubber industry, abandoned in the face of Southeast Asian plantation competition, was revived (somehow) during world war II when Allied access to Asian supplies was restricted. The demographic collapse haphazard development of the Portuguese colony produced a fragmented social landscape. A condition easy to be interpreted as an institutional purpose by an outsider. But in view of the fact that the cardinal frontier was more a product of Conquest than an original condition, the unknown qualities of the region and its peoples - those elements that in part justify the frontier characterization, are too highly variable to sustain the adequacy of the term.

In Amazonia, there was not a single frontier similar to that of the USA but a plethora of 'crystal frontiers', developed through centuries linked to the extraction of different types of raw materials. Each 'wave' was based on new desires, knowledge, systems, technologies, forms of social organization and incorporation of new actors that interacted with groups that were already there. Each group with their own space and ecological production strategies.

Flows and flows back are common phenomena in Amazonia. It is a sea more than a land. In these movements, some social groups have disappeared, others have affirmed, fallen, fled. In Amazonia, frontiers were not only open and closed, but they were constantly reopened and closed again. This is a perennial phenomenon marked by the arrival of new actors in search of new resources and with the consequent re-territorialization. A secular phenomenon which is more intense than ever nowadays (Schmink and Wood 1984 and 1989; Little 2001).

\section{Objectives}

The hypothesis supported by this article, in urban and territorial studies, is that the common characterization of Amazonia as a frontier should be deeply revised. This territory has been part of the capitalist world system for more than five centuries and may be better interpreted as a composition of enclave environments, economies and ecologies, whose relationships to external political and socio-economic powers is deep-rooted and far less fragile than the frontier usage implies.

The history of the Amazon is full of examples of moving subjects: nomadism, group migration, long-distance trade, explorations, forced displacement, colonization and labor migration, all this is part of the Amazonian social history.

In Amazonia several spatial production competing processes are superimposed and many social groups are involved in a constitution / reconstitution process, as well as in negotiations in a poorly-known biophysical context.

The constant flow of subjects and resources inside and outside the border generates unstable dynamics, making the field of powers unpredictable and even chaotic.

In urban and territorials studies, the equation of frontier and Amazonia has some of the obsessive qualities of a fixed idea. Its repeated invocation, at different scales, in many branches of academic inquiry on this territory may reflect as much as an attitude towards a long marginalized territory (and its inhabitants) as it does a carefully thought-out model of regional disparity and uneven development. Amazonia and its inhabitants (especially Indios) carry a particular symbolic weight that is paradoxically both central to on-going nation-building projects and, at the same time, it is suggestive of a remote exoticism. There is an expanded frontier metaphor that, while having real content, also contributes to a counterproductive mythologizing that ignores socio-spatial changes in colonial and post-colonial Amazonia. It is possibile to affirm that this term works as a familiar device for distancing Amazonia from particular 'development processes' characterizing this region. While there is broad acknowledgment that there are 'many Amazonias', and hence many 'frontiers', an emphasis on the enclave nature of these 'many Amazonias' may help clarify what is systematic about the 'integration' of the region. The frontier metaphor, a partial trope, minimises the temporal.

In urban, studies dominated by developmentalist or ecological protection issues, where attention is typically focuses on highly circumscribed object of analysis (a river or forest with high ecological values or a set of dispersed urban settlements or mining areas), the notion of frontier continues to maintain significant utility because of the seemingly sharp demarcation of discrete socio-spatial worlds and the consequent absence of unifying or different conceptual framework for Amazonian territories and societies. (Jackson 1975; Overing 1981, Viveiros de Castro 1996, Pullan 2011).

From this perspective as well, the continuous accommodation of what is regularly portrayed as an inexorable and sparsely provisioned natural realm is a constant reminder of the presence of an implacable frontier.

From a socio-spatial perspective frontiers have come and gone, and the degree to which the frontier concept is perspective-dependent in an ontological sense is overtaken by a more prosaic cui bono / material interest-group sense.

In terms of the extraction of primary resources, for instance, Amazonian frontiers have appeared, disappeared and been reinvented over hundreds of years in response to shifts in global availability of prosaic resources. These kind of frontiers are less a matter of local cultures construction, although they no doubt impinge on many different cultural perspectives, than stipulations of global economic interests for which Amazonia provides certain strategic possibilities. Yet the widespread usage of the frontier metaphor in urban 
studies tends to enforce a generic notion of the term.

One consequence of that usage is that the same term in reference to diverse phenomena obscures what has actually taken place in Amazonia in favor of fragmented perspectivism. Nevertheless many Amazonian existing indigenous populations may reflect diverse socio-cultural realities and, therefore, live within their own histories (or non-histories). There has been a transformative colonial history that has shaped, in still poorly understood ways, their contemporary conditions of existence. Yet the persistent frontier notion grants priority to spatial arrangements and dispositions as though these provide adequate mapping.

A clear illustration of how the frontier/spatial perspective occludes the temporal provided in the growing literature on anthropogenic in Amazonian pre-history (see Balée 1994). The continued force/plausibility of the frontier metaphor, however in undeniable. Even in the recent past, since the inception of the Manta-Manaus corridor, for example, and with the extensively documented radical transformation of social and biological landscapes in the region, there has hardly been a lessening of the overall characterization of the 'frontier green hell'.

This misalignment of a politically key notion of frontier (which underscores the importance of a spatial frontier to the viability of Indio societies), and a methodological frontier (that is one that signifies the particular features of the dominant spatial mode of discourse), is reflected in the marginal position that non-Indio, rural Amazonians (campesinos, mestizos, kinds of typological status rather than 'culture') maintain. They are not seen as being on the frontier, but as literally constituting the frontier, i.e., eroding the barriers between 'intact', atomized forest societies and a set of encroaching urban actors, forces and imaginaries.

\section{Methods}

An analysis of the literature concerning Amazonian territorial constructions highlights many factors that seem to contribute to the continued plausibility of the frontier notion, although the major one is the insistent portrayal of Amazonia as a passive natural space acted upon, brought to life by non-Amazonians: conquistadores, missionaries, the state, foreign capital, NGOS. This active/passive contrast is concordant with modernization impetuses according to which Amazonia was to be 'integrated'. The naturalistic associations of Amazonia, widely familiar since the Victorian era, when, for example, Arthur Conan Doyle's Lost World defined the image of the neo-tropical frontier, for popular consumptions, have long offered self-serving opportunities for bringing culture and civilization to the benighted. Within Ecuador and Peru in particular, the ambition for political hegemony in the Amazonian region has exploited the threat of other nations' assault in 'the frontier'. Finally, the ideological maintenance of a permanent Amazonian frontier has been useful from the point of view of a predatory state's offers of free land and resources to interests willing to 'colonize' on behalf of the nation (Foweraker 1981; Velho 1972; Souza Martins 2002; Brown, L. A., Digiacinto, S., Smith, R., Sierra, R. 1994). Bunker's (1985) analysis of extractive activities describes the seeming functionality of the frontier concept as an expression of a dysfunctional state, and the more recent book by Balick and Posey (2006) illustrates that the ubiquity of the frontier concept offers little in terms of illustrating the trajectories within the intensified research climate of the past thirty years from the vantage point of a number of disciplines.

These various frontier associations are well represented in literature, many seen as expressions of an overarching geophysical rationale in a region in which even the territorial referent is complicated by the uncertain relationships between water and land. An example is the contrast between varzea and terra firme.

These notions or connotations of frontier seem to take priority over more precise historical contextualization, but at the same time they harbor the implication of impeding, final defeat or breaching of the frontier boundaries. The arena in which that apocalyptic take is most realistic is with respect to indigenes. Yet adherence to a deferred notion of the final breaching of the insulating frontier obscures the extent to which that frontier has already been breached. It is in this respect that the notion of enclave maintains the explanatory force of frontier, but also draws attention to the sequence of selective incorporations of the region.

This is most marked in relation to the extractive activities associated with particular Amazonian products, mainly extractive, but also agricultural and pastoral. A case in point would be the 'gold rush' in the 1980s (see Cleary 1990), widely depicted as a frontier strongly analogous with the gold frontier of California a century earlier, but with very specific localized efforts as well as the more broad-reaching - and more metaphorical - impacts familiar to the idiom of boom-bust historiography customary in popular historical accounts. Similarly, Anderson's (2004) of Amazon estuary rum manufacture illustrates the use of rum as a trade good in the reinforcement of the interior commercial frontier of Brazilian western Amazonia. But here, the frontier is a given one; what is compelling about the account is the set of linkages that rum provides within the enclave or rural-urban production complex in pre-Transamazonian Highway.

These, and many other examples, are hardly esoteric, but they are overshadowed by the 'forntieresque' idiom according to which, like many things in the popular as well as official-bureaucratic imaginations of the region, all will become clear 'in the future'. In the confusion of conceptual frontiers (as between Amazonia 'the interior' and an encroaching national society) and more literal frontiers, it is easy to overlook the fact that future long ago arrived in 
Amazonia.

The conceptual, cultural frontiers that have been seen in Ecuador or Brazil from both the green hell (inferno verde) and piranhalandia of Amazonia have been repeatedly cloned. The late twentieth century has also seen such cloned frontiers in the successive appearance of the foodstuff frontier (Velho 1972), the cattle frontier (Foweraker 1981; Hecht and Cockburn 1989), and the soya frontier not to mention timber, iron, bauxite, gold, etc. These are 'commodity frontiers' that have arisen not because they represent newly discovered, frontier resources, instead have achieved prominence because of the decline or exhaustion of analogous resources elsewhere in the tropical or semi-tropical world (e.g. declining timber resources in Central Africa and Southeast Asia).

The frontier discourse misrepresents the vulnerability of Amazonia by portraying these resources as intrinsic to discovery in the region as opposed to their availability as a function of comparative advantage and weak-non-existent regulation. If any frontier term is correct it is 'frontier of legal non-enforcement'.

\section{Results}

There is a strong association between the Amazonian frontier orthodoxy and arguments expressed in Meggers' (1971) Amazonia: Man and Culture in a Counterfeit Paradise. In the first instance there is a similarity in regional characterization. Secondly, there is the implication of permanence of the frontier state of affairs. Thirdly, there is the implication that the characterization, whether frontier or false paradise, is an original condition.

Those three elements have been substantially modified since the publication of that book, but there is an implacability to the position strongly expressed in replies to various revisionist suggestions. From within the cultural ecological strand within which Meggers herself is strongly positioned, there is much greater insight into the diversity of Amazonia subregions. In general a strong case for greater heterogeneity and differentiation within the 'humid neo-tropical forest' designation (see Moran 1993) can be made.

The permanence of the rigidities of 'counterfeit paradise' and its long tenure have both been queried by diverse kinds of work (demography, historiography, archeology) on the region (e.g. Denevan 1976; Lathrap 1970; Heckenberger 2005; Porro 1996; Roosevelt 1989). One major topic to which attention is drawn in this work is the fact that many of the frontier aspects of the region are not natural givens, but are social products. Not least among these is the demographic collapse that took place in the very early phases of the construction of colonial society such that the frontier aspects long assumed to be manifestations of an original condition in Amazonia may better reflect the thoroughness of the social and biological assault on the region and its peoples.

In keeping with the frontier motif that dominates Amazonian historiography, the rubber industry is typically depicted as 'boom', an episodic event, yet while toward the end of the 19th century there was an intensification of the rubber trade (monumentalised in the opera house in Manaus). The rubber industry actually lasted for about one hundred years. It brought the development of extensive commercial and transport links within the region with it significant urbanization qn integration into the most advanced technological sectors of global economy, all this enabling the dispersion of many immigrants from other regions of Brazil.

What these and other examples illustrate is the frailty of an attempted pan-regional, adequate frontier characterization. Instead, they draw attention to the long-standing existence of a non-uniform social topography in which various kinds of societies, dominated in number and type by disenfranchised peasantries, much more identifiable with post-frontier societies although unrecognized as such in terms of innovation. Amazonia was already articulated as a frontier regardless of how it was perceived on the ground by 'frontier Amazonians'.In, particular, in the social studies literature focused on the analysis of non-Indio Amazonians there has been an undeniable frontier aspect. This is well illustrated in the early work of Moran (1981), for example, and is also found in a literature derived from a sort of 'peasant strategies' approach (Lisansky 1989). But the frontier in all such work co-exists with another kind of peasant society that shares little of that frontier characterization or orientation (see Harris 2000; Nugent 1993) where instead a historic rather than spatial dynamic seems to prevail.

\section{Discussion and Conclusions}

Among the consequences of an overly generous metaphorical reading of the frontier notion in Amazonia there is a systematic downgrading of Amazonian peoples and societies as they are portrayed in a general literature (i.e non-scholarly) ineptly drawn from specialist sources. Indigenous peoples are often portrayed as hidden by the frontier, when maybe, it is possible to say they are hiding from the frontier in the sense that adjacency to white society strongly correlates with conflicts. In terms of Ecuadorian peasant Amazonians, the durable frontier metaphor has aided in denying the historical depth of non-indigenous peoples and the integrity of the various mestizo societies of the area. Where indigenous are typically represented as, in principle, in harmony with the great Amazonian bio-sphere, peasants are typically regarded as invaders. Another untoward consequence of the overwhelming frontier characterization is the seemingly affinity Amazonia is projected as having for extractivist activities. Some examples are the advance of 
the soya industry being the most recent, and by many reckonings lethal, addition to extensive agro-pastoral, timber-felling, fishing and mining activities. The widely recorded and acknowledged illegality of much Amazonian industry is seen as a typical and hard to mitigate consequence of the region's frontier status. The active space of deregulation and weak legal enforcement is not intrinsic to Amazonia, but that impression is certainly reinforced by the regular invocation of frontier.

The dominance of frontier metaphors in part represents the success of some selective naturalistic readings of tropical socio-spatial realities. The contingencies of many aspects of social existence may become self-reproducing pathologies when territorial planning policies are premised on the notion that the role of the state is to 'tame' the frontier. Conditions - as in the case of the Manta-Manaus corridor program - that create frontiers often emerge when none existed beforehand. What has happened since has been the creation of many new forms of frontier, but these are far less the spatial interface of a marginal regional and encroaching state than specific enclave developments which, in their aftermath, produce residua frontiers, degraded biosocial space. A tradition of representing Amazonian peoples as frontier-occupiers or definers has the effect of defining them as contingent and largely subject to the backdrop against which they are cast. While there can be little disputing over the effects of various kinds of externalities in shaping the lives of modern Amazonians, the contingency of the frontier characterization is contradicted by the sistematicity of the forces that have acted upon them since the colonial era. The relationship between colonizer and colonized has not been just a spatial one, and to summarize it as such - on the frontier - distorts what is actually known from the historical and ethnographic record.

\section{REFERENCES}

[1] Anderson, S., Of rum and the Amazon: the traditional sugar-cane industry and its demise. In S. Nugent nd M. Harris (eds) Some Other Amazonians: Perspectives on Modern Amazonia. London: Institute for the Study of the Americas, 145-177, 2004

[2] Balée, W., Footprints of the Forest: Ka’apor ethnobotany the historical ecology of plant utilization by an Amazonian people. New York: Columbia University Press, 1994

[3] Balick, M. and Posey, D. (eds), Human Impacts on the Amazon. New York: Columbia University Press, 2006

[4] Brown, L. A., Digiacinto, S., Smith, R., and Sierra, R., Frameworks of urban system evolution in frontier settings and the Ecuador Amazon. Geogr. Res. Forum 14, 72-96, 1994

[5] Cleary, D., Anatomy of the Amazon Gold Rush, Macmillan, london 1990
[6] Denevan, W., The Native populations of America, 1492. University of Wisconsin Press, Madison, 1972

[7] Doyle, A. C., The Lost World. London: Hodder and Staughton, London, 1912

[8] Foweraker, J., Struggle for the Land, Cambridge University Press, Cambridge, 1982

[9] Fuentes C., La frontera de cristal, Punto de Lectura, Ciudad de México, 2007.

[10] Harris, M., Life on the Amazon: The Anthropology of a Brazilian Peasant Village. Oxford University Press, Oxford, 2000

[11] Hecht, S. and Cockburn, A., Fate of the Forest: developers, destroyers and defenders of the Amazon, Verso, London, 1989.

[12] Heckenberger, M., The Ecology of Power: culture, place and personhood in the Southern Amazon. AD 1000-2000. London: Routledge, Londom 2005.

[13] Jackson, J., Recent ethnography of indigenous northern lowland South America, Annual Review of Anthropology, Vol. 4. 307-340, 1975

[14] Lathrap, D., The Upper Amazon. New York: Preaeger; New York, 1970

[15] Lisansky, J., Migrants to Amazonia: Migrants on the Amazonian Frontier, Westview Press, Boulder, 1989

[16] Little, P., Territorial Struggles on Perennial Frontiers, The Johns Hopkins University Press, Baltimore, MD, and London, 2001

[17] Meggers, B., Amazonia: Man and Culture in a Couterfeit Paradise: Aldine, Chicago, 1971

[18] Moran, E., Developing the Amazon. University of Indiana Press, Bloomington, 1981

[19] Moran, E., Through Amazonian Eyes, University of Iowa Press, Iowa City, 1993

[20] Nugent, S., Amazonian Caboclo Society: An Essay on Invisibility and Peasant Economy, Berg, Oxford, 1993.

[21] Nugent, S. and Harris, M. (eds), Some Other Amazonians: Perspectives on Modern Amazonia. London: Institute for the Study of the Americas, London, 2004.

[22] Overing, J., Amazonian anthropology. Journal of Latin American Studies 13:1, 151-165, 1981

[23] Porro, A., O Povo das Aguas: ensaios de etnohistoria Amazonica.: Vozes, Petropolis, 1996

[24] Pullan, W., Frontier urbanism: the periphery at the centre of contested cities, The Journal of Architecture, 16: 1, 15-35, 2011

[25] Ramos, A., The hyperreal Indian, Serie Antropologica. Department of Anthropology, University of Brasilia, Brasilia, 153-171, 1992

[26] Roosevelt, A., Resource management on Amazonia before conquest, Advances in Economic Botany 7:30-62, 1989 
[27] Schminck, M., Wood, C., Frontier Expansion in Amazonia. University of Florida Press, Gainesville, 1984.

[28] Schminck, M., Wood, C., Contested Frontiers Amazonia. Columbia University Press, New York, 1984

[29] Souza Martins, J., Representing the peasantry? Struggle for / about land in Brazil. Journal of Latin American Studies 29:3 / 4, 2002

[30] Tannenbaum, F., Slave and Citizen: The Negro in the Americas. Ramdom House, New York, 1946

[31] Turner, F. J., The Frontier in American History, Henry Holt, New York, 1921.

[32] Velho, O., Frentes de expansão e estrutura agrária, Zahar, Rio, 1972.

[33] Viveiros de Castro, E., Images of nature and society in Amazonian Ethnology, Annual Review of Anthropology Vol. 25, 179-200, 1996.

[34] Wallerstein. I., The Modern World System Vol. 1. Academic Press, New York, 1974. 